\title{
Redescription of Mehdiella microstoma and description of Mehdiella petterae sp. n., with a new definition of the genus Mehdiella Seurat, 1918 (Nematoda: Pharyngodonidae)
}

\author{
Salah Bouamer ${ }^{1}$, Serge Morand ${ }^{2}$ and Robert Bourgat ${ }^{1}$ \\ ${ }^{1}$ Groupe Pluridisciplinaire des Sciences, Université de Perpignan, 52 Av. de Villeneuve, 66860 Perpignan, France; \\ ${ }^{2}$ Centre de Biologie et d'Ecologie Tropicale et Méditeranéenne, Laboratoire de Biologie Animale (UMR 5555 CNRS), \\ Université de Perpignan, 52 Av. de Villeneuve, 66860 Perpignan, France
}

Key words: Nematoda, Mehdiella, Pharyngodonidae, Testudo graeca, Testudo hermanni, Morocco, Spain

\begin{abstract}
The generic diagnosis of Mehdiella Seurat, 1918 is emended based on study and redescription of Mehdiella microstoma (Drasche, 1884) from the caecum of Testudo graeca Linnaeus, 1758 collected in Settat, Morocco and on study and description of a new species, Mehdiella petterae sp. n., from the large intestine of Testudo hermanni (Gmelin, 1789) collected in Catalonia, Spain. Scanning electron microscopy (SEM) studies revealed substantial differences in the structure of the mouth and the caudal end, and made possible to differentiate the new species from the others. SEM studies showed the real and sound characteristics of the genus Mehdiella, namely number of anal papillae 2 instead of 3, post-anal papillae pedunculate or sessile instead sessile.
\end{abstract}

Palaearctic testudinids are parasitised by several genera and species of oxyuroids (Seurat 1918, Petter 1966, Bouamer and Morand 2000). Among them, the genus Mehdiella was established by Seurat (1918) for Oxyuris microstoma Drasche, 1884 and O. uncinata Drasche, 1884 when he revised the genus Tachygonetria and described many new species. In a revision of the genus Tachygonetria, Thapar (1925) considered the presence of a caudal point in the male as the only character distinguishing Mehdiella and Tachygonetria and transferred the above two species to Tachygonetria, but Yorke and Maplestone (1926) maintained the genus Mehdiella. Walton (1942) and Dubinina (1949) agreed with Thapar (1925) that Mehdiella is a synonym of Tachygonetria. Petter $(1961,1966)$ and Petter and Quentin (1979) recognised the genus Mehdiella.

In this paper, we redescribe $M$. microstoma from Testudo graeca Linnaeus, 1758 and describe a new species $M$. petterae sp. n. from Testudo hermanni Gmelin, 1789.

\section{MATERIALS AND METHODS}

Nematode parasites were collected from 18 specimens of Testudo graeca from Morocco, and from a single specimen of T. hermanni from Spain. Nematodes were preserved in $70 \%$ ethanol before being cleared with lactophenol for study. Figures were made with the aid of a drawing tube. Nematodes were dehydrated by passing them through a graded ethanol series to absolute ethanol. Residual humidity was extracted to the critical point (M scope 500). The scanning electron microscope used was a HITACHI S 520 under $20 \mathrm{kV}$. Measurements are given in micrometres unless otherwise stated.

\section{RESULTS}

Mehdiella microstoma (Drasche, 1884) Figs. 1-11

Synonyms: Oxyuris microstoma Drasche, 1884; Oxyuris draschei Stossich, 1898; Macracis papillosa Forstner, 1960 (see Petter 1966); Tachygonetria weissi Seurat, 1918 (see Dittmann 1965); Tachygonetria microstoma (Drasche, 1884), Thapar, 1925.

General. Body thick, medium-sized, straight in female and slightly curved in male. Cuticle thick, transversely striated; excretory pore ventral, pre-bulbar in female post-bulbar in male. Head distinct with cuticle not striated; buccal cavity absent. Oesophagus elongate, widening slightly at anterior end, connected by short neck to large spherical bulb which contains strongly curved cuticularised plates. Many thin, conical spines or teeth in anterior wall of bulb.

Female. Body stout, terminating posteriorly in long conical tail. Oral opening dorso-ventral, bordered by 3 lips (Figs. 2, 8): one left lip, divided in middle to stretch from ventral side as far as dorsal side; two right lips, divided in equal size. Cephalic sense organs consisting of inner circle of 6 nerve endings, papillae not prominent, 2 on left side and 4 on right side. Outer circle of 4 sub-lateral papillae triangle-shaped with nerve ending, and 2 amphids. The oesophagus formed by 3 plates: 1 right and 2 left (Fig. 3). Vulva behind middle of the body, vagina long and directed anteriorly. Uterus curving, posteriorly passing into narrow oviduct. In 30 individuals, eggs not observed. Anus developed; nerve ring not distinguished; tail elongated. 

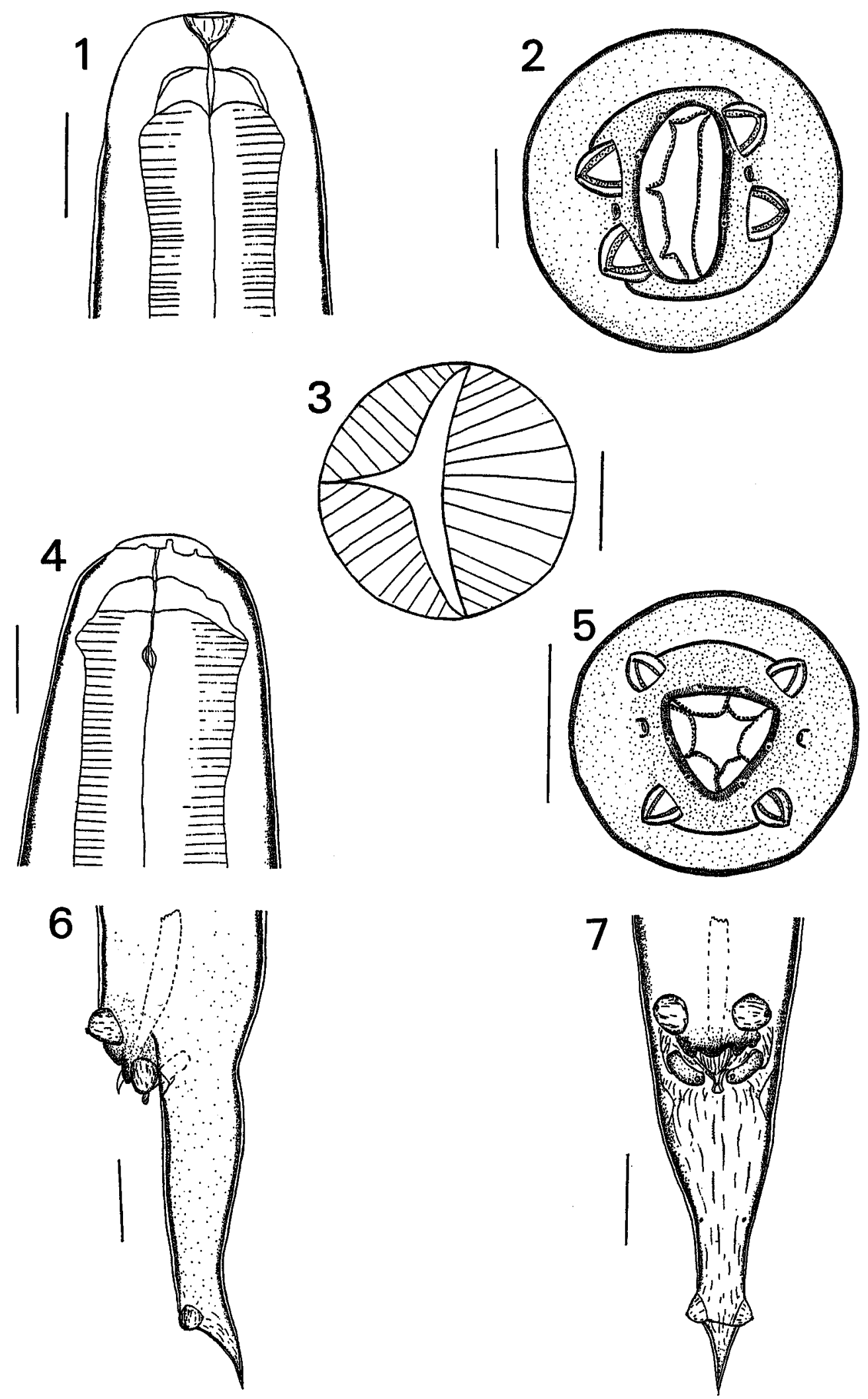

Figs. 1-7. Mehdiella microstoma. Fig. 1. Anterior end of female. Fig. 2. Cephalic end, en face of female. Fig. 3. Oesophageal sectors of female. Fig. 4. Anterior end of male. Fig. 5. Cephalic end, en face of male. Fig. 6. Posterior end of male, lateral view. Fig. 7. Posterior end of male, ventral view. Scale bars: Figs. 1, 4, 6, $7=50 \mu \mathrm{m}$; Figs. 2, 3, $5=25 \mu \mathrm{m}$. 

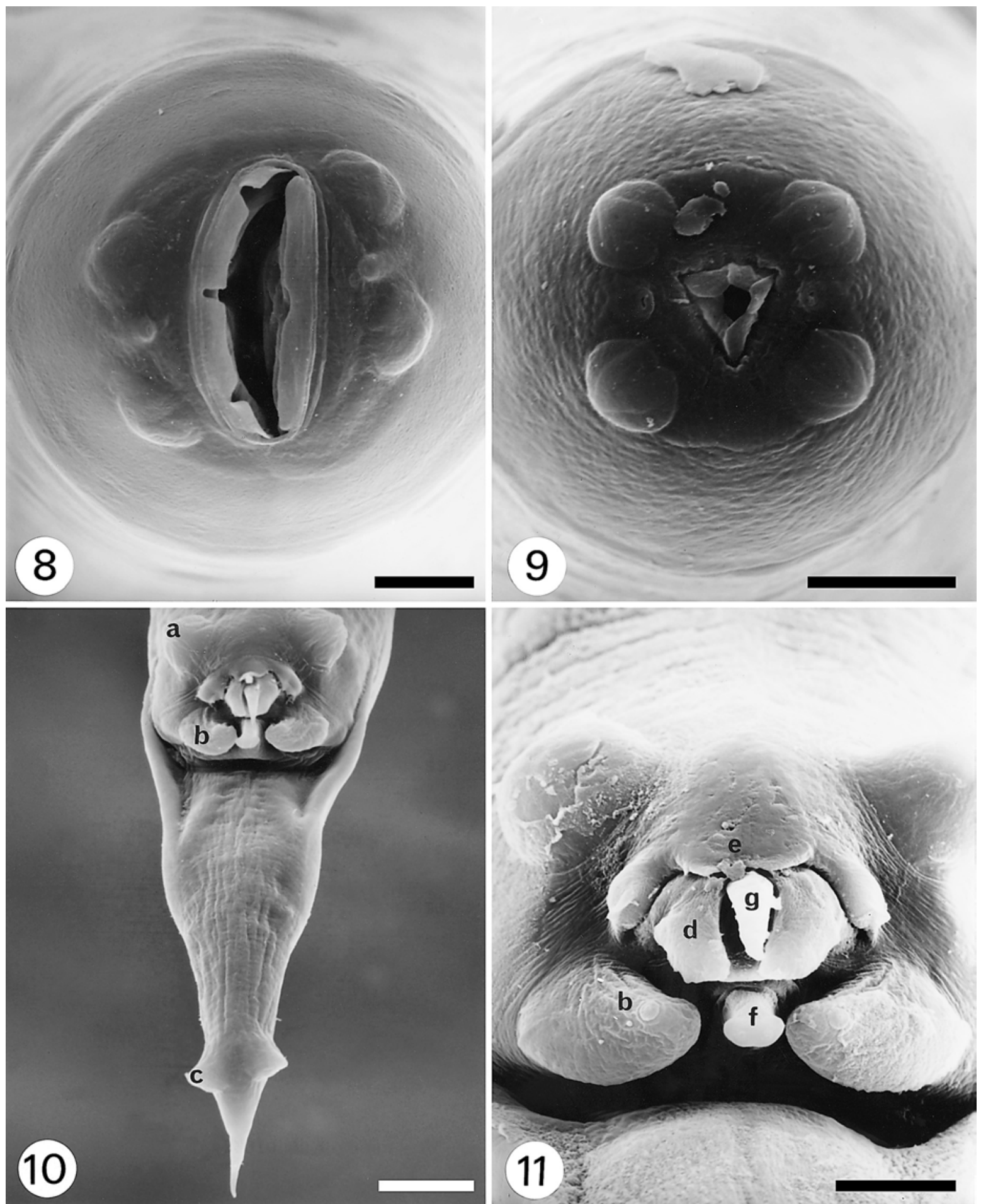

Figs. 8-11. Mehdiella microstoma, scanning electron micrographs. Fig. 8. Cephalic end of female. Fig. 9. Cephalic end of male. Fig. 10. Caudal end of male, ventral view. Fig. 11. Cloacal view of male. a - pre-anal papilla; b - post-anal papilla; $c$ - caudal papilla; $d$ - anterior lip; e - pre-anal membrane; $f$ - posterior lip; $g$ - spicule. Scale bars: Figs. 8, $10=20 \mu$ m; Figs. $9,11=10$ $\mu \mathrm{m}$. 
Measurements of 4 specimens: Length $8.7-9.2 \mathrm{~mm}$. Maximum width 482-558 near midbody. Nerve ring 274-284 and excretory pore $2.358-2.452 \mathrm{~mm}$ from anterior end. Oesophagus $2.169-2.358 \mathrm{~mm}$ long, with bulb $218 \times 255-227 \times 255$ in size. Tail 691-776 long. Vulva 4.6-4.9 $\mathrm{mm}$ from anterior end.

Male. Smaller than female. Oral opening subtriangular, bordered by 6 lips, 2 dorsal and 4 sub-ventral (Figs. 5, 9). Cephalic sense organs consisting of inner circle of 6 nerve endings, papillae not prominent, the outer circle of 4 sub-lateral papillae triangular-shaped with nerve ending, and 2 amphids. Caudal papillae situated slightly before end of tail. Cloaca with 2 pairs of genital papillae: one pair, sessile rosette-shaped preanal and one pair elongate post-anal (Figs. 10, 11). Spicule short, needle-shaped. Gubernaculum Y-shaped.

Measurements of 4 specimens: Length 6.0-6.4 mm. Maximum width 249-270 near midbody. Nerve ring 237-274 from anterior end. Excretory pore 1.890-2.110 $\mathrm{mm}$ from anterior end. Oesophagus 0.918-1.040 mm long, with bulb $109 \times 109-113 \times 120$ in size. Tail 162176 long. Spicule 105-109 long.

H o s t: Testudo graeca Linnaeus, 1758.

$\mathrm{S}$ it e of infection: Large intestine.

I n f e c t i o n : Prevalence: 11\%. Intensity: 220 (180-260).

L o c a 1 i t y : Settat, Morocco, $32^{\circ} 30^{\prime} 45^{\prime \prime} N, 7^{\circ} 45^{\prime} 30^{\prime \prime} \mathrm{W}, 22$ July 1999, Salah Bouamer coll.

$\mathrm{S}$ p e c i m e n s d e p o s i t e d : 4 females and 4 males deposited in the Muséum d'Histoire Naturelle (Paris): Coll. No. $838 \mathrm{HF}$.

Remarks. Our redescription gives new information on buccal and caudal structures of Mehdiella microstoma. The outer papillae in female and male are triangular-shaped with nerve ending described as quadrangular by Petter (1961). In male, there are two pairs of genital papillae, one pair, sessile rosette-shaped pre-anal, and one pair elongate post-anal. Petter (1961) mentioned three genital pairs: one pair pre-anal, one pair ad-anal and one pair post-anal. Petter (1961) did not mention the number of lips in male, which are six small lips. Finally the gubernaculum is Y-shaped, which was mentioned to be V-shaped by Petter (1961).

Mehdiella microstoma has been reported by Drasche (1884), Seurat (1918), Thapar (1925), Dyk et Dyková (1956), Forstner (1960), and Schad et al. (1960) from Testudo graeca. Dubinina (1949) studied this species from Testudo horsfieldii Gray, 1844. Baruš and Johnson (1973) reported this species in Testudo hermanni. Up to this time this helminth is restricted to the Palaearctic region and hosts are members of the genus Testudo: T. graeca in Europe and North Africa; T. horsfieldii in Afghanistan, Caspian steppe (Markov et al. 1962, Sharpilo 1976), Iran and Tadjikistan (see Petter 1966); and T. hermanni in Albania (see Baruš and Johnson 1973).

\section{Mehdiella petterae sp. $\mathrm{n}$.}

Figs. 12-20

General. Nematoda, Oxyuroidea, Pharyngodonidae, Mehdiella. Small-bodied nematode, slender, slightly curved on the ventral side. Cuticle thick, distinctly striated and detached from the body wall behind cephalic region, forming small vesicular swelling. Body wall compressed behind head.

Male (holotype and 4 paratypes): Head distinct with cuticle not striated, oral opening hexagonal, surrounded by 6 lips without anterior styliform process; buccal cavity short, without denticles.

Cephalic sense organs consisting of outer circle of 4 nerve endings, papillae not prominent, inner circle not observed, 2 amphids (Figs. 14, 17).

Oesophagus long; nerve ring surrounding oesophagus in anterior third, excretory pore posterior to bulb. Caudal alae of medium size. Tail pointed at apex (Figs. 15, 16, 18-20) and bearing at extremity a pair of ventral caudal papillae, 2 pairs of equal pedunculate papillae surrounding the anus: one pair pre-anal, one pair post-anal. Pre-anal membrane with two lateral lobes between pre-anal papillae, each lobe forming globular heap without nerve ending. Anterior lip of anus formed by two separate lobes, posterior lip of anus with central nipple. Extremity of spicule visible between pre-anal membrane and anterior lip, spicule a high-heeled boot, with pointed end. Robust tail terminated by nipple (Figs. 19, 20). Gubernaculum enlarged, U-shaped.

Measurements (holotype with 4 paratypes in parentheses): Length 1.4 (1.1-1.5) mm. Maximum width 105 (120-180) near midbody. Nerve ring 127 (131-150) from anterior end. Excretory pore 469 (461-600) from anterior end. Oesophagus 450 (525-578) long. Tail 41 (38-45) long. Spicule 60 (56-68) long.

T y p e h o st: Testudo hermanni Gmelin, 1789.

$\mathrm{S}$ it e of infection: Large intestine.

Intensity of infection: 35 .

T y p e 1 o c a 1 i t y: South Catalonia, Spain, $41^{\circ} 23^{\prime} 14^{\prime \prime N}$, $2^{\circ} 11^{\prime} 17$ 'E, 17 December 1993, Dr. Carlos Feliu coll.

$\mathrm{S} p$ e c i m e n s d e p o s i t e d: Holotype and 4 paratypes deposited in the Muséum d'Histoire Naturelle (Paris): Coll. No. 839 HF.

E t y m o lo g y : The species is named in honour of Dr. Annie J. Petter.

Remarks. Mehdiella petterae is easily distinguishable from the other species of the genus by possessing pedunculate anal papillae. Mehdiella petterae resembles M. dubinini Skrjabin et Schikhobalova, 1951 from Testudo horsfieldii in Tadjikistan, by its forked spicule with a pointed end. In M. dubinini there are on each lip two transparent stylet-like processes at the anterior margin end. Mehdiella petterae also differs from $M$. dubinini in the presence of medium caudal alae. 

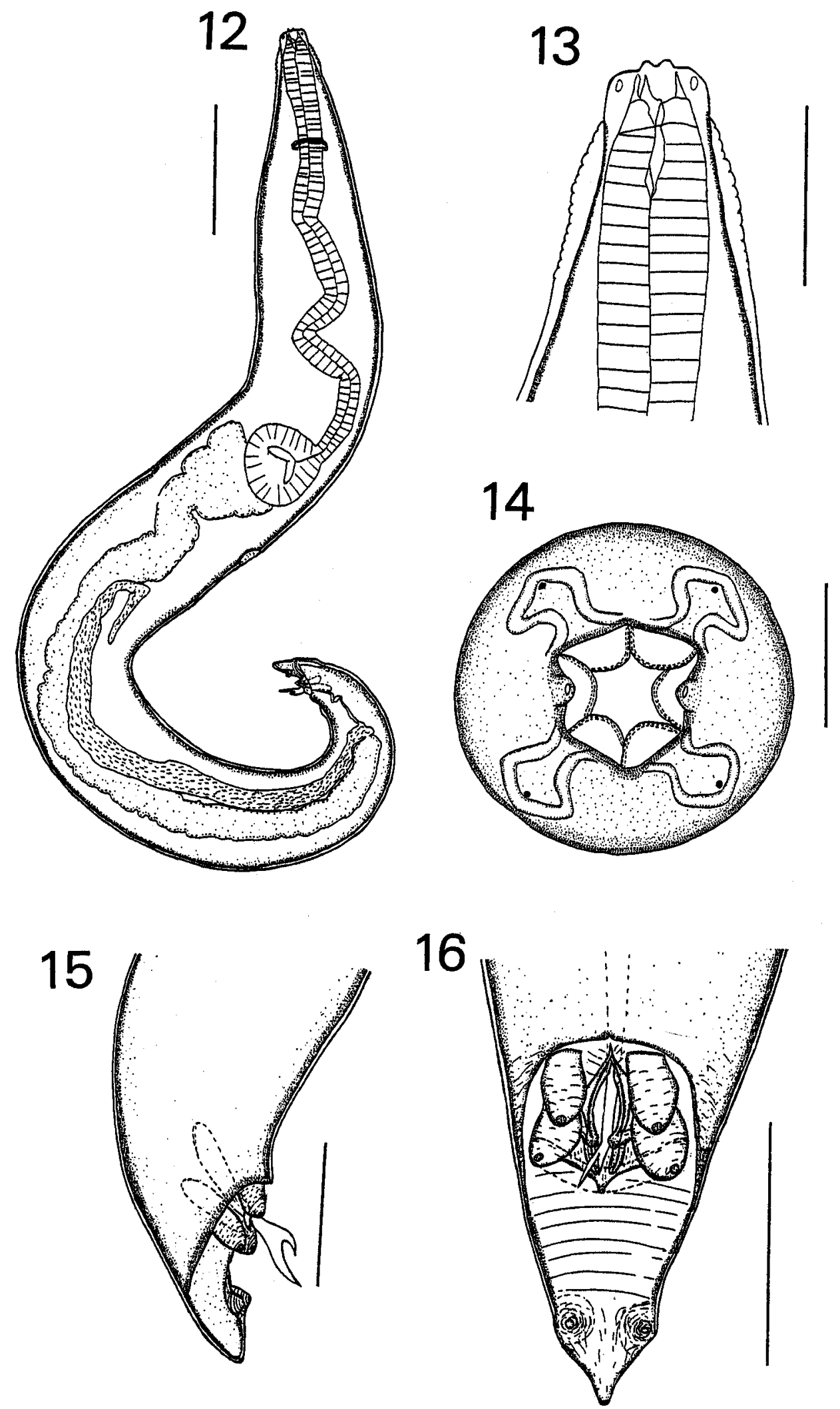

Figs. 12-16. Mehdiella petterae sp. n., male holotype. Fig. 12. Entire specimen, lateral view. Fig. 13. Anterior end. Fig. 14. Cephalic end, en face. Fig. 15. Posterior end, lateral view. Fig. 16. Posterior end, ventral view. Scale bars: Fig. $12=100 \mu \mathrm{m}$; Figs. $13,15,16=50 \mu \mathrm{m}$; Fig. $14=25 \mu \mathrm{m}$. 

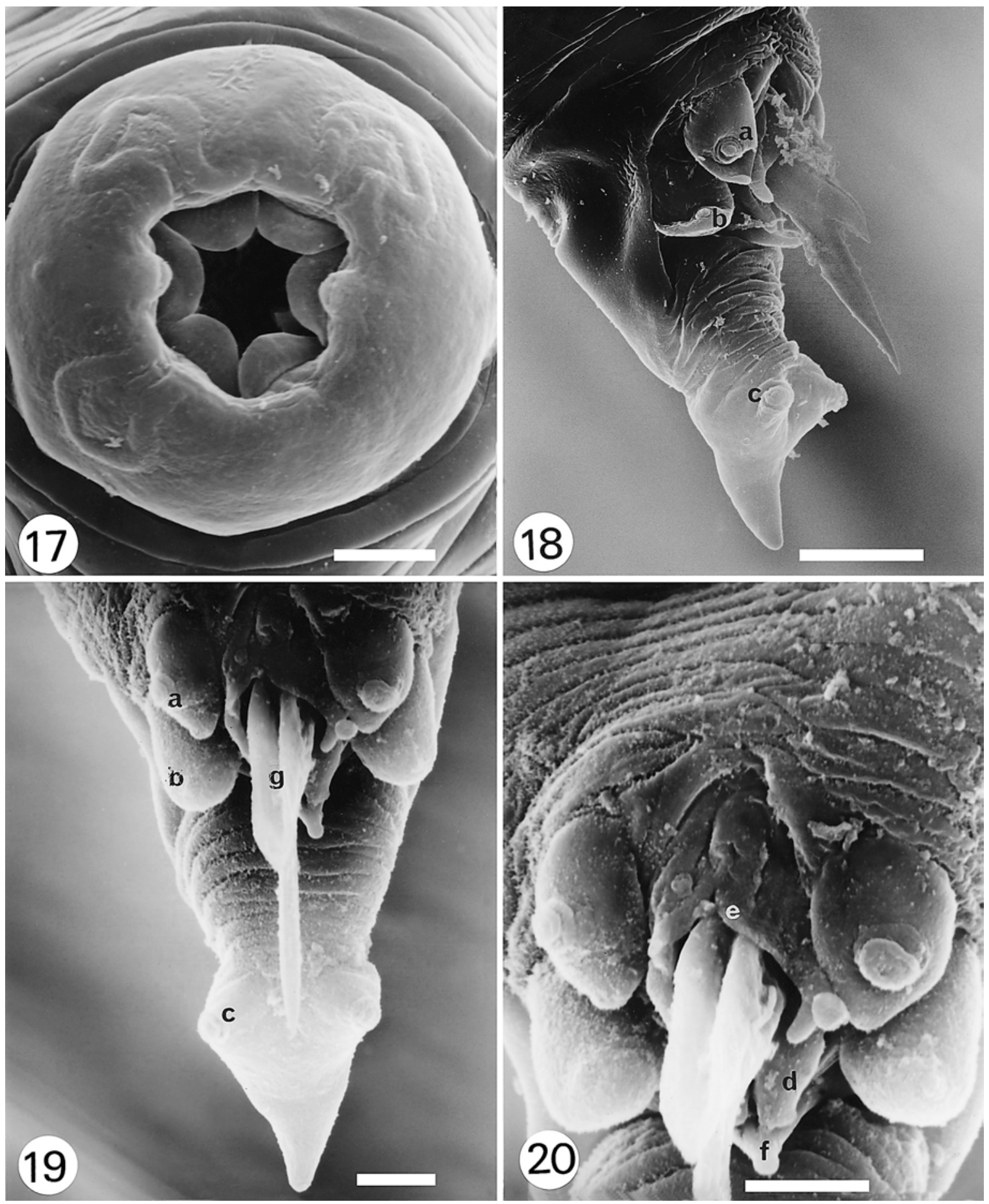

Figs. 17-20. Mehdiella petterae sp. n., scanning electron micrographs of male. Fig. 17. Cephalic end. Fig. 18. Caudal end, lateral view. Fig. 19. Caudal end, ventral view. Fig. 20. Cloacal view. a - pre-anal papilla; b - post-anal papilla; c - caudal papilla; $\mathrm{d}$ - anterior lip; e - pre-anal membrane; f-posterior lip; g - spicule. Scale bars: Figs. 17, $20=5 \mu \mathrm{m}$; Figs. $18,19=10 \mu \mathrm{m}$.

Ainsworth (1990) showed the existence of polymorphism in males of Skrjabinodon trimorphi Ainsworth, 1990, and Skrjabinodon poicilandri Ainsworth, 1990. She observed two morphs in each species. The main morphological differences between the male morphs concerned the presence/absence of tail append- age spine, spicule and genital cone. All these differences noted by Ainsworth (1990) may be artifacts due to fixation and manipulation. These artifacts were seen in M. microstoma and $M$. petterae with tail appendage spine broken and genital cone compressed, and were also observed in species of the genera 
Tachygonetria, Thaparia and Alaeuris (Bouamer, unpubl.).

The differences that we noted between the new species and other species of the genus concern the structure of cephalic end, the shape and position of genital papillae, the shape and size of caudal alae and the size of body.

\section{Emended diagnosis of the genus}

The use of a scanning electron microscope allowed to recognise that what had been described as ad-anal papillae are simple lobes that lack nerve endings. The new diagnosis of the genus is: cuticle compact, transversely striated, smooth or covered with hairs. Sometimes with a vesicular widening at cephalic end. Pharynx short. Oesophagus cylindrical, passing into bulb.
Male. Mouth with six lips. Caudal end not truncate ventrally near anus, ending in dorsal conical point with a pair of large sessile papillae in its posterior third. Two pairs of sessile or pedunculate papillae: one pair preanal, one pair post-anal. Caudal alae narrow or medium. Spicule short, simple or bifurcate. Gubernaculum V-, U-, or Y-shaped.

Female. Tail conical, short. Vulva situated at a short distance behind mid-body. Two uteri. Oviparous. Eggs large, numerous, ellipsoidal, segmented at deposition. Parasites of reptiles.

T y p e s p e c i e s : Mehdiella microstoma (Drasche, 1884)

Acknowledgements. We thank Dr. Annie Petter for her helpful comments on an earlier version of this manuscript. We thank Prof. M. Adamson and an anonymous referee for helpful comments and suggestions.

\section{REFERENCES}

AINSWORTH R. 1990: Male dimorphism in two new species of nematode (Pharyngodonidae: Oxyurida) from New Zealand lizards. J. Parasitol. 76: 812-822.

BARUŠ V., JOHNSON S. 1973: Notes on Mehdiella microstoma (Drasche, 1884) from Testudo hermanni Gmelin, 1788. Folia Parasitol. 20: 139-140.

BOUAMER S., MORAND S. 2000: Oxyuroids of Palearctic Testudinidae: new definition of the genus Thaparia Ortlepp, 1933 (Nematoda: Pharyngodonidae), redescription of T. thapari thapari, and descriptions of two new species. Comp. Parasitol. 67: 169-180.

DITTMANN I. 1965: Untersuchungen über Magen-DarmNematoden aus der griechischen Landschildkröte (Testudo hermanni L.). Helminthologia 6: 181-203.

DRASCHE R.V. 1884: Nematoden aus Testudo graeca. Verh. K. K. Zool.-Bot. Ges. Wien 33: 325-330.

DUBININA M.H 1949: Ecological studies on the parasite fauna of Testudo horsfieldii Gray from Tadjikistan. Parazitol. Sb. 11: 61-97. (In Russian.)

DYK V., DYKOVÁ S. 1956: Hlístice nalezené v dovezených želvách řeckých (Testudo graeca L.). Česk. Parasitol. 3: 43-48.

FORSTNER M.J. 1960: Ein Beitrag zur Kenntnis parasitischer Nematoden aus griechischen Landschildkröten. Z. Parasitenkd. 20: 1-22.

JOHNSON S. 1973: Some oxyurid nematodes of the genera Mehdiella and Thaparia from the tortoise Testudo hermanni. Folia Parasitol. 20: 141-148.

MARKOV G.S., IVANOV V.P., NIKULIN V.P., CHERNOBAI V.F. 1962: Helminth parasites of reptiles from Volga-delta and Caspian steppe. Tr. Astrakh. Zap. 6: 145-172. (In Russian.)

ORTLEPP R.J. 1933: On some South African reptilian oxyurids. Onderstepoort J. Vet. Sci. 1: 99-114.
PETTER A.J. 1961: Redescription et analyse critique de quelques espèces d'Oxyures de la tortue grecque (Testudo graeca L.). Diversité des structures céphaliques. Ann. Parasitol. Hum. Comp. 10: 648-671.

PETTER A.J. 1966: Équilibre des espèces dans les populations de Nématodes parasites du côlon des tortues terrestres. Mém. Mus. Natl. Hist. Nat., Paris, sér. A, Zool. 39: 1-252.

PETTER A.J., QUENTIN J.C. 1976: Keys to the genera of the Oxyuroidea. CIH Keys to the Nematode Parasites of Vertebrates. No. 4. R.C. Anderson, A.C. Chabaud and S. Willmott (Eds.), Commonwealth Agricultural Bureaux Farnham Royal, Slough, UK, pp. 11.2-11.3.

SCHAD G.A., KUNTZ R.E., WELLS W.H. 1960: Nematode parasites from Turkish vertebrates. Can. J. Zool. 38: 949963.

SEURAT L.-G. 1918: Contribution à l'étude de la faune parasitaire de la Tunisie. Nématodes. Arch. Inst. Pasteur Tunis 10: 243-275.

SHARPILO V.P. 1976: Parasitic Worms of the Reptilian Fauna of the USSR. Izdat. Naukova Dumka, Kiev, USSR, 287 pp. (In Russian.)

SKRJABIN K.I., SCHIKHOBALOVA A.A., MOZGOVOI A.A. 1951: Key to Parasitic Nematodes. Vol. II. Oxyurata and Ascaridata. Izdat. Akad. Nauk SSSR, Moscow, 631 pp. (In Russian.)

STOSSICH M. 1898: Saggio di una elmintologica di Trieste. Program. d. Civ. Scuola r. Sup., Trieste, 162 pp.

THAPAR G.S. 1925: Studies on the oxyurid parasites of reptiles. J. Helminthol. 3: 83-150.

WALTON A.C. 1942: Some oxyurids from a Galapagos tortoise. Proc. Helminthol. Soc. Wash. 9: 1-17.

YORKE W., MAPLESTONE P.A. 1926: The Nematode Parasites of Vertebrates. J. \& A. Churchill, London, 536 pp.

Accepted 30 October 2000 